\title{
Author Correction: Bmi1 is essential in Twist1-induced epithelial-mesenchymal transition
}

Muh-Hwa Yang, Dennis Shin-Shian Hsu, Hsei-Wei Wang, Hsiao-Jung Wang, Hsin-Yi Lan, Wen-Hao Yang, Chi-Hung Huang, Shou-Yen Kao, Cheng-Hwai Tzeng, Shyh-Kuan Tai, Shyue-Yih Chang, Oscar Kuang-Sheng Lee and Kou-Juey Wu

Correction to: Nature Cell Biology https://doi.org/10.1038/ncb2099, published online 5 September 2010.

In the version of Supplementary Fig. $3 c$ originally published with this Article, the authors mistakenly duplicated a blot from Supplementary Fig. 3b. The correct versions of these figures are shown below. In addition, two independent repeats of the experiments presented in Supplementary Figs. $3 \mathrm{~b}$ and 3c, showing results consistent with those originally reported, have been deposited in Figshare (10.6084/m9.figshare.7545263).

b

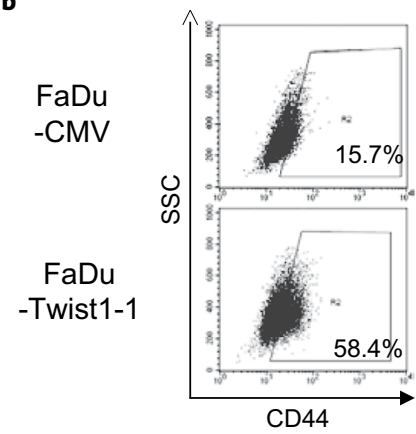

Original

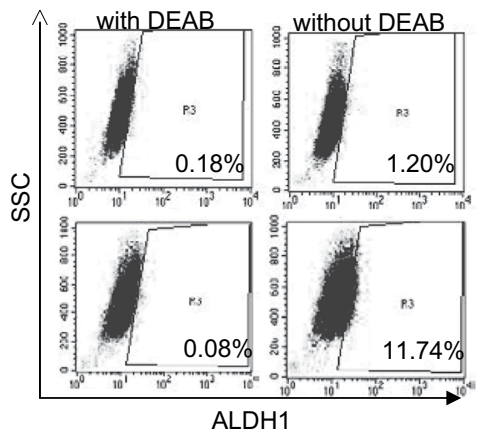

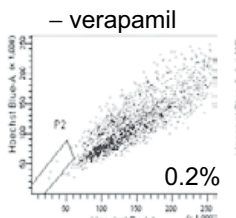
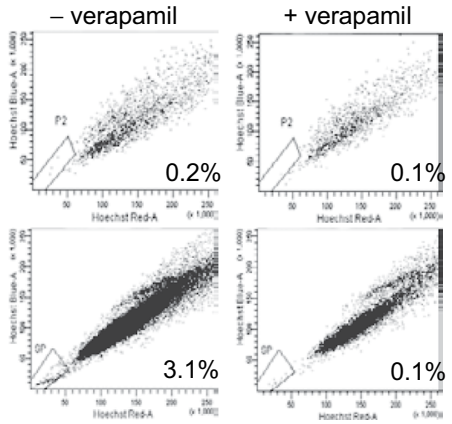

Supplementary Fig. 3b | Original.

c

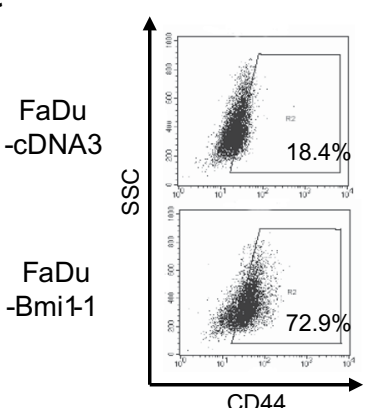

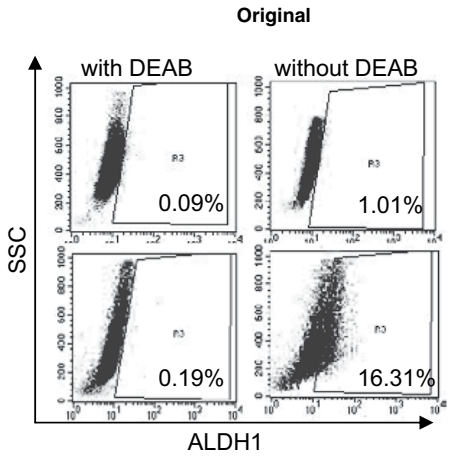

Corrected

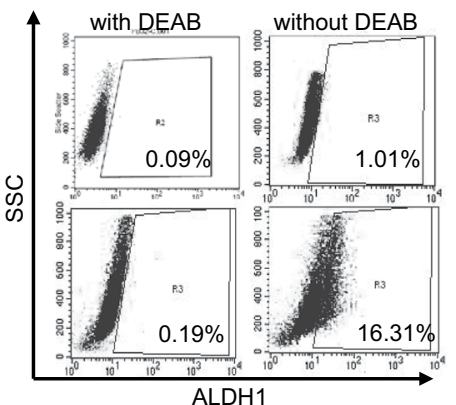

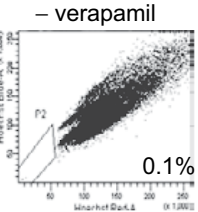
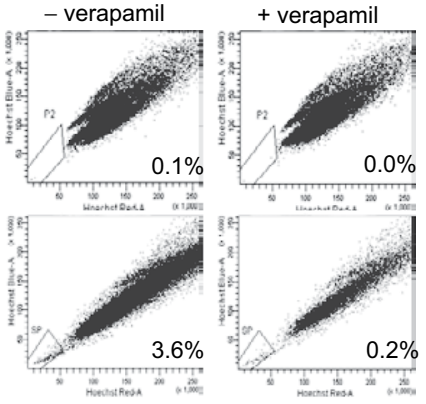

- verapamil
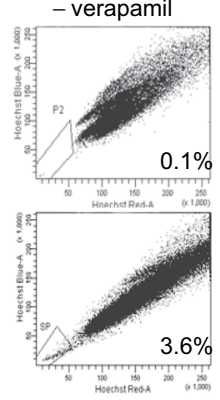
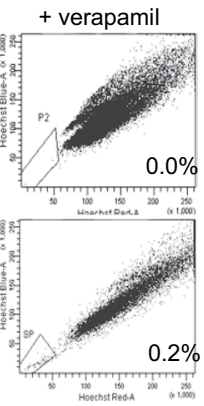

Supplementary Fig. 3c | Original and Corrected.

Published online: 4 March 2019

https://doi.org/10.1038/s41556-019-0290-9 